\title{
Anaphylaxis from bee pollen supplement
}

\section{Amanda Jagdis MD, Gordon Sussman MD}

A 30-year-old woman was referred to the allergy clinic after having an anaphylactic reaction. Before the reaction, the patient had recently started taking three health supplements: bee pollen, omega 3-6-9 oil and vitamin D3. Ten minutes after she took her second dose of supplements, the patient's eyelids, lips and throat began to swell, she had difficulty swallowing, and hives started to develop. The patient also had shortness of breath and felt faint, lightheaded and weak. The symptoms resolved after emergency treatment with epinephrine and diphenhydramine, and fluids given intravenously. The supplements were stopped and no further reactions occurred.

The patient had a history of seasonal allergic rhinoconjunctivitis, particularly during the summer months, but was otherwise healthy. She was a nonsmoker and took no regular medications. She had no history of allergies to foods, drugs, latex or insect venom, and no family history of atopy. The patient's clinical examination was unremarkable.

A skin allergy test (i.e., a prick/scratch test) showed a strong positive result for the bee pollen supplement (20-mm wheal, 41-mm erythema), and Timothy grass (20-mm wheal, 37-mm erythema). Results of similar tests for birch, ragweed, foods and the other two supplements were negative. Histamine control testing gave a positive result.

We advised our patient to avoid bee pollen supplements and other products containing

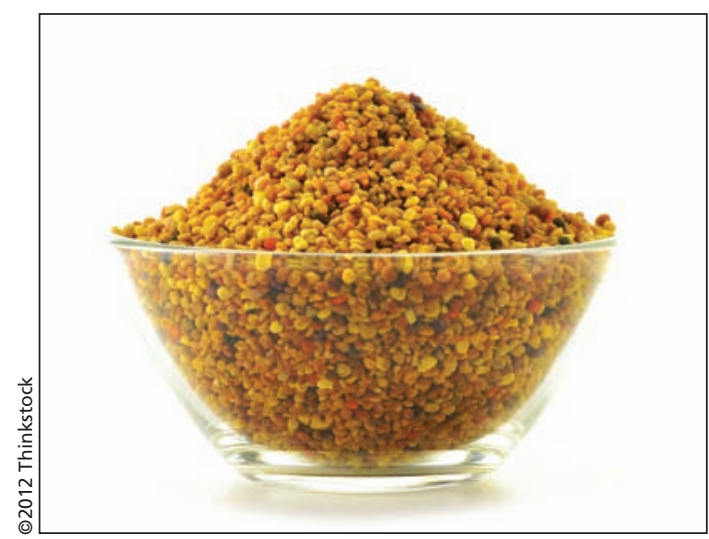

grasses or pollens. We prescribed an epinephrine auto-injector and reviewed its correct usage with our patient.

\section{Discussion}

The use of complementary and naturopathic medicine is prevalent across Canada. Data from a 2010 Ipsos Reid poll for Health Canada suggest that $73 \%$ of Canadians take natural health products on a regular basis. ${ }^{1}$ However, some natural products carry a risk of adverse effects of which patients may not be aware.

Bee pollen is a natural health product consisting of pollen granules collected from plants by bees. It is available for purchase in Canada and is marketed for a variety of purposes, from longevity to weight loss. Anaphylaxis associated with the consumption of bee pollen has been reported in the literature, but many people remain unaware of this potential hazard. Most of the evidence for this association comes from case reports and one small case-control study. The first description in the literature of allergy to bee pollen was by Cohen and colleagues in 1979. ${ }^{2}$ The authors reported acute systemic allergic reactions in three patients after the ingestion of bee pollen. Further testing showed that all three patients were allergic to short ragweed, a member of the family Compositae. ${ }^{2}$ Analysis of two commercial bee pollen products used by the patients showed that they both contained pollen from dandelion, another member of the Compositae. ${ }^{2}$ It was suggested that allergenic
Competing interests: Gordon Sussman is a consultant for Pfizer; he has received grants from Novartis and CSL Behring; he has received payment for lectures from the Ontario Society of Asthma, Allergy and Immunology. No other competing interests were declared.

This article has been peer reviewed.

Correspondence to: Dr. Gordon Sussman, gsussman@rogers.com

CMAJ 2012. DOI:10.1503 /cmaj.112181 
cross-reactivity between Compositae pollens was the cause for the allergic reactions.

The family Compositae is very large and includes such species of flowering plants as dandelion, goldenrod, mugwort, ragweed and sunflower (Box 1). ${ }^{3}$ Although ragweed and mugwort produce airborne pollen (i.e., anemophilous plants) and are a common cause of allergies, most of the plants in the family Compositae pollinate via insect vectors (entomophilous plants) and are not implicated in allergies. ${ }^{3}$ In general, low allergenic cross-reactivity has been found between ragweed and other members of the family Compositae. ${ }^{3}$

Since the allergy was first described, other bee pollen-associated allergic reactions have been captured through case reports and surveillance for adverse drug reactions. Between 2002 and 2007, the Italian national surveillance system for natural health products received 18 reports of suspected adverse reactions associated with propolis (a bee pollen product). ${ }^{4}$ Of these reactions, 16 involved cutaneous or respiratory allergy, 6 required treatment in or admission to hospital, and 2 were life-threatening. ${ }^{4}$

Although many reactions, such as that of our patient, have been associated with a history of pollen allergy, other scenarios have been described. A case of life-threatening anaphylaxis after ingesting bee pollen was reported in a patient with no history of allergies. ${ }^{5}$ Another case of anaphylaxis occurred in a patient who had previously undergone immunotherapy with pollen and dust mite allergen for allergic rhinitis. ${ }^{6}$ Although the symptoms of allergic rhinitis had improved, the immunotherapy did not prevent the patient from having an anaphylactic reaction (with urticaria, dyspnea and throat tightness) upon initial ingestion of bee pollen. ${ }^{6}$

\section{Box 1: Examples of allergenic plants of the} family Compositae ${ }^{3}$

- Ambrosia artemisiifolia (short ragweed)

- Ambrosia bidentata (southern ragweed)

- Ambrosia trifida (giant ragweed)

- Artemisia vulgaris (common mugwort)

- Artemisia tridentate (giant sagebrush)

- Artemisia annua (annual wormwood)

- Aster chinensis (starwort)

- Baccharis halimifolia (sea-myrtle)

- Chrysanthemum leucanthemum (oxeye daisy)

- Chrysanthemum morifolium (chrysanthemum)

- Helianthus annuus (sunflower)

- Solidago gigantea (goldenrod)

- Tanacetum vulgare (tansy)

- Taraxacum officinale (dandelion)

\section{Possible mechanisms}

In Greece, Pitsios and colleagues investigated the association between pollen and bee pollen allergy through a case-control study in which 145 patients with atopy and 57 healthy or nonatopic controls underwent skin testing to five bee pollen extracts and four commercial pollen extracts: olive (Olea europea), a mixture of grasses (Dactylis glomerata, Poa pratensis, Holcus lanatus, Lolium perenne and Phleum pratense), a mixture of Parietaria officinalis and Parietaria judaica, and mugwort (Artemisia vulgaris). ${ }^{7}$ Seventy-three percent of the patients with atopy had positive skin test reactions to one or more of the bee pollen extracts. Among the patients with atopy, there was statistically significant correlation between positive skin test reactions to bee pollen extract and skin test reactions to olive, grass and mugwort pollens.

An analysis of the bee pollen samples used in the Greek study showed the presence of pollen from both entomophilous (e.g., members of the Leguminaceae, Rosaceae, Umbelliferae and Oleaceae) and anemophilus (some members of the Oleaceae and members of the Gramineae) plants. ${ }^{7}$ When ingested at the suggested dose, the bee pollen extracts could contain a large amount of airborne pollen $\left(0.4 \times 10^{6}\right.$ to $6.4 \times 10^{6}$ pollen grains per gram of bee pollen). ${ }^{7}$

Because respiratory allergies are generally caused by anemophilous plants, rather than entomophilous plants, the presence of airborne pollen in bee pollen supplements may contribute to the risk of allergic reaction, particularly if the bee pollen contains a substantial amount of airborne pollen to which an individual is sensitized. ${ }^{?}$

Other suggested mechanisms for reaction include the potential for cross-reactivity between common epitopes on entomophilous and anemophilous pollens from the same botanical family, or reaction to insect antigens that may be present in bee products.

\section{Controversies}

Our patient had a life-threatening allergic reaction after ingesting bee pollen. In conjunction with counselling about avoiding allergens, we prescribed an epinephrine auto-injector and asked the patient to carry it continuously in case of a future reaction. However, given the relatively avoidable nature of the presumed trigger, it could be argued that prescribing an epinephrine auto-injector may not have been necessary. There has been controversy over the frequency with which such devices are prescribed, with some authors suggesting that they have been overprescribed. ${ }^{8.9}$ Our decision to prescribe an auto-injector was made on an individual basis, given the life-threatening nature of 
our patient's reaction. However, it should be acknowledged that some controversy exists as to whether this is a necessary course of action.

\section{Conclusion}

Although bee pollen is marketed as a natural health supplement, it has the potential to cause substantial allergic reactions when ingested by patients with pollen allergy. Often, skin tests showing reactivity to common airborne pollens correlates with reactivity to bee pollen. ${ }^{7}$ Health care providers should be aware of the potential for reaction, and patients with pollen allergy should be advised of the potential risk when consuming these products - it is not known who will have an allergic reaction upon ingesting bee pollen.

\section{References}

1. Natural health product tracking survey - 2010 final report. Ottawa (ON): Prepared for Health Canada by Ipsos Reid; 2010. Available: http://epe.lac-bac.gc.ca/100/200/301/pwgsc-tpsgc /por-ef/health/2011/135-09/report.pdf (accessed 2011 July 12).

2. Cohen SH, Yunginger JW, Rosenberg N, et al. Acute allergic reaction after composite pollen ingestion. J Allergy Clin Immunol 1979;64:270-4

3. Weber RW. Cross-reactivity of plant and animal allergens. Clin Rev Allergy Immunol 2001;21:153-202.

4. Menniti-Ippolito F, Mazzanti G, Vitalone A, et al. Surveillance of suspected adverse reactions to natural health products: the case of propolis. Drug Saf 2008;31:419-23.

5. Geyman JP. Anaphylactic reaction after ingestion of bee pollen. J Am Board Fam Pract 1994;7:250-2.

6. Greenberger PA, Flais MJ. Bee pollen-induced anaphylactic reaction in an unknowingly sensitized subject. Ann Allergy Asthma Immunol 2001;86:239-42.

7. Pitsios C, Chliva C, Mikos N, et al. Bee pollen sensitivity in airborne pollen allergic individuals. Ann Allergy Asthma Immunol 2006;97:703-6.

8. Unsworth DJ. Adrenaline syringes are vastly over prescribed. Arch Dis Child 2001;84:410-1.

9. Keogan M, Khalib K, Edgar JD, et al. Prescription of epinephrine auto-injectors - Can we reach a consensus? Ir Med J 2008; 101:1-8.

Affiliations: From the Department of Medicine (Jagdis), University of British Columbia, Vancouver, BC; St Michael's Hospital (Sussman), Division of Allergy, Clinical Immunology, Toronto, Ont.; and the Department of Medicine (Sussman), University of Toronto, Toronto, Ont.

Contributors: Amanda Jagdis interviewed the patient and wrote the case report. Gordon Sussman supervised the patient interview, obtained written consent from the patient and assisted in writing and revising the case report. Both authors approved the final version of the manuscript submitted for publication. 